\title{
Nascent ZW Sex Chromosomes in Thecadactylus rapicauda (Reptilia, Squamata, Phyllodactylidae)
}

\author{
Michael Schmid $^{a}$ Claus Steinlein $^{a}$ Thomas Haaf ${ }^{a}$ Abraham Mijares-Urrutia ${ }^{b}$ \\ ${ }^{a}$ Department of Human Genetics, Biocenter, University of Würzburg, Würzburg, Germany; ${ }^{b}$ Centro de \\ Investigaciones en Ecología y Zonas Áridas, Universidad Nacional Experimental Francisco de Miranda, \\ Santa Ana de Coro, Venezuela
}

\section{Key Words}

Gecko $\cdot$ Thecadactylus rapicauda $\cdot$ ZW sex chromosomes

\begin{abstract}
The chromosomes of the turnip-tailed gecko Thecadactylus rapicauda from the Falcón State in northern Venezuela were examined by means of conventional staining, a variety of banding techniques and in situ hybridization with an $18 \mathrm{~S}+$ 285 rDNA probe. In female specimens, C-banding analyses detected a cryptic W sex chromosome-associated interstitial heterochromatic segment which is absent in the $Z$ sex chromosome. These ZW sex chromosomes are considered to be in a nascent stage of morphological differentiation and are absent in T. rapicauda collected in Guatemala. The amount, location and fluorochrome affinities of constitutive heterochromatin, the position of the nucleolus organizer region, and the genome sizes of female and male individuals were determined. The previously published cytogenetic data on T. rapicauda are discussed.

(c) 2014 S. Karger AG, Basel
\end{abstract}

Reptiles are characterized by an astonishing variability of reproductive and sex-determining mechanisms. These include parthenogenesis, gonochorism, viviparity, oviparity, genetic sex determination with $\mathrm{XY} \sigma^{-1} / \mathrm{XX}$ \% or $\mathrm{ZZ}^{-1} /$ ZW \% sex chromosomes, and temperature-dependent sex determination [for reviews, see Olmo, 1986; Ezaz et al., 2009a; Gamble, 2010]. In the case of lizards (order Squamata, suborder Sauria), cytogenetic data are available for 29 of the 32 families [Olmo and Signorino, 2005; Ezaz et al., 2009a; Vidal and Hedges, 2009]. In 7 families (Dibamidae, Gymnophthalmidae, Iguanidae, Pygopodidae, Scincidae, Sphaerodactylidae, and Teiidae), 78 species have been found with XYor/XXo sex chromosomes and 37 species with multiple sex chromosomes of the $\mathrm{X}_{1} \mathrm{X}_{2} \mathrm{Y}^{7} /$ $\mathrm{X}_{1} \mathrm{X}_{1} \mathrm{X}_{2} \mathrm{X}_{2}$ ? type. In 6 families (Agamidae, Bipedidae, Chamaeleonidae, Lacertidae, Phyllodactylidae, and Varanidae), 61 species were detected with $\mathrm{ZZo}^{\prime} / \mathrm{ZW}$ \% sex chromosomes and 4 species with multiple sex chromosomes of the $\mathrm{Z}_{1} \mathrm{Z}_{1} \mathrm{Z}_{2} \mathrm{Z}_{2} \mathrm{O}^{7} / \mathrm{Z}_{1} \mathrm{Z}_{2} \mathrm{~W}$ ? type. Finally, in the family Gekkonidae, 2 species with XYơ/XX? sex chromosomes and 11 species with ZZo'/ZW\% sex chromosomes were discovered so far [see data compilation by Ezaz et al., 2009a].

\section{KARGER}

E-Mail karger@karger.com www.karger.com/cgr
(C) 2014 S. Karger AG, Basel

$1424-8581 / 14 / 1434-0259 \$ 39.50 / 0$
Michael Schmid

Department of Human Genetics, University of Würzburg

Biozentrum, Am Hubland

DE-97074 Würzburg (Germany)

E-Mail m.schmid@biozentrum.uni-wuerzburg.de 
Fig. 1. Adult individual of T. rapicauda collected in the Falcón State in northern Venezuela.

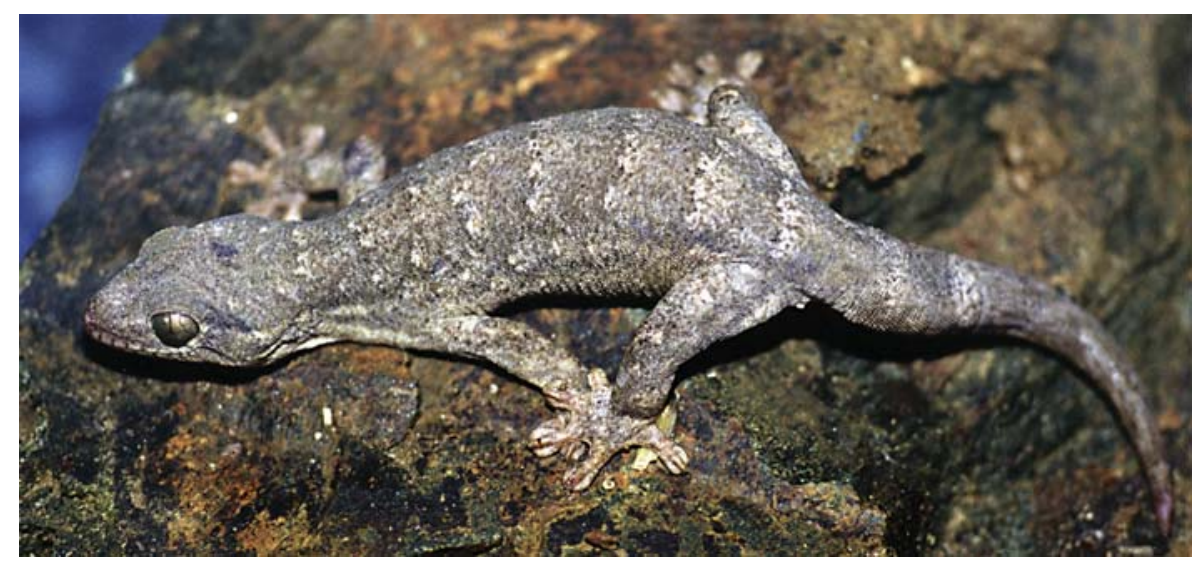

Lizard sex chromosomes exhibit a notable diversity in morphology and differentiation. A variety of mechanisms involved in the differentiation of heteromorphic sex chromosomes were found. These include inversions, centric fusions, accumulation of constitutive heterochromatin, and translocations between autosomes and sex chromosomes [Cole et al., 1967; King, 1977, 1981; Bickham, 1984; Moritz, 1984; Olmo, 1986; Olmo et al., 1987]. In many lizard species with genetic sex determination, homomorphic XY and ZW sex chromosomes seem to exist. However, as the present study on the neotropical gecko Thecadactylus rapicauda shows, banding analyses can detect subtle but clear structural differences between the otherwise homomorphic sex chromosomes.

Turnip-tailed geckos of the genus Thecadactylus are distributed from southeastern Mexico across most of Central America and tropic South America, including the Lesser Antilles [Russel and Bauer, 2002]. Currently, 3 species are recognized: T. rapicauda, T. solimoensis and T. oskrobapreinorum [Bergmann and Russell, 2007; Köhler and Vesely, 2011]. T. rapicauda (fig. 1) is a large (length up to $12 \mathrm{~cm}$ ), relatively common, nocturnal, carnivorous and arboricolous gecko with heavily fringed digits and retractable claws. The dorsum is mottled gray, the venter cream colored. The vertically elliptical pupil is centered in a golden- or silver-colored iris. The thick conical tail may be lost easily, and the regenerated tail is anteriorly wider than the stump, resulting in the characteristic turnip shape. T. rapicauda frequently inhabits human-modified environments. A synthesis of the natural history of this species was published by Avila-Pires [1995].

\section{Materials and Methods}

\section{Animals}

Ten mature specimens of T. rapicauda $\left(4 \sigma^{\prime}, 6\right.$ \%) were collected in the Falcón State in northern Venezuela during 2 expeditions in 1997 and 1998 (table 1). All animals were collected during the daytime from trunks and branches of trees or walls. The captured specimens were kept in humid cloth bags, air-filled plastic bags with wet leaf litter, or plastic boxes until they were processed for chromosomes and erythrocytes in a temporary cytogenetic laboratory established in the biological field station 'Rancho Grande' located in the Henri Pittier National Park on the Cordillera de la Costa (Aragua State, Venezuela). Tissues obtained for chromosome preparations and determination of the nuclear DNA contents were transferred to 1.8 - $\mathrm{ml}$ plastic tubes (Nunc), stored at $4^{\circ} \mathrm{C}$ or $-20^{\circ} \mathrm{C}$ and transported to the laboratories in Würzburg (Germany) packed in dry ice. Additionally, 2 mature specimens ( $1 \sigma^{\prime}, 1$ O) from an unknown collection site in Guatemala were purchased in 1997 from a specialized animal dealer, and their chromosomes were prepared in the laboratories in Würzburg. All procedures with the living animals strictly conformed to the guidelines established by the Animal Care Committees.

\section{Chromosome Preparation and Banding Analyses}

Mitotic metaphases were prepared directly from the bone marrow and intestines of all animals after in vivo colchicine treatment. Male meiotic chromosomes were obtained from testes. The techniques used for the preparation of cell suspensions, hypotonic treatment and fixation of the cells have been described previously [Schmid et al., 2010]. C-banding of constitutive heterochromatin, $\mathrm{AgNO}_{3}$ labeling of nucleolus organizer regions (NORs), direct staining of chromosomes with the fluorochromes quinacrine mustard, DAPI and Hoechst 33258, and fluorescence counterstaining with distamycin A/DAPI and distamycin A/mithramycin (table 1) were also performed according to Schmid et al. [2010].

\section{Localization of $18 S+28 S$ Ribosomal DNA Sequences}

The hybrid plasmid pXlr 101A, which contains inserted ribosomal RNA (rRNA) gene sequences from Xenopus laevis, was used as a source of ribosomal DNA (rDNA). The plasmid pXlr 101A is a derivative of pBR322 (4.3 kb) into which 1 complete rRNA gene $(12 \mathrm{~kb})$ has been inserted. The inserted DNA sequence, obtained 
Table 1. Cytogenetic data available for T. rapicauda

\begin{tabular}{|c|c|c|c|c|c|c|c|}
\hline Country & Specimens $^{\mathrm{a}}$ & Locality of sampling & $2 n$ & $\mathrm{FN}$ & $\begin{array}{l}\text { Sex } \\
\text { chromosomes }^{b}\end{array}$ & Techniques $^{c}$ & Study \\
\hline Venezuela & 19 & Cerro Montecano, Península de Paraguaná, Falcón State & 44 & 44 & ZWo & $1-9$ & present study \\
\hline Venezuela & 1 ㅇ, $10^{7}$ & Pueblo Nuevo, Península de Paraguaná, Falcón State & 44 & 44 & ZW & $1-9$ & present study \\
\hline Venezuela & $3 \%, 30^{\pi}$ & City of Coro, Falcón State & 44 & 44 & ZW $/ Z Z Z^{\circ}$ & $1-9$ & present study \\
\hline Venezuela & 1 우 & Cataratas de Hueque, Sierra de San Luís, Falcón State & 44 & 44 & ZW & $1-9$ & present study \\
\hline Guatemala & $19,10^{7}$ & unknown & 44 & 44 & no & 1,2 & present study \\
\hline Venezuela & 1 \&, $3 \sigma^{\prime \prime}$ & San Felipe, Yaracuy State & 44 & 44 & $?$ & 1 & Soma et al., 1975 \\
\hline Venezuela & $2 \sigma^{\pi}$ & 17 km NW Caripito, Monagas State & 42 & 44 & $?$ & 1 & McBee et al., 1984 \\
\hline
\end{tabular}

a The 2 specimens from an unknown collection site in Guatemala were purchased from a specialized animal dealer. The 2 specimens examined by McBee et al. [1984] are deposited in the Texas Cooperative Wildlife Collection (TCWC), Texas A\&M University, as Nos. 59723 and 59724.

b Small heteromorphism in the ZW sex chromosomes only recognizable by C-banding.

${ }^{c} 1$ = Conventional staining; 2 = C-banding of constitutive heterochromatin; 3 = Ag-staining of NORs; $4=$ quinacrine fluorescence; 5 = distamycin $\mathrm{A} /$ mithramycin fluorescence; $6=\mathrm{DAPI}$ fluorescence; $7=$ distamycin A/DAPI fluorescence; $8=$ Hoechst 33258 fluorescence; $9=$ FISH with $18 \mathrm{~S}+28 \mathrm{~S}$ rDNA probe.

by digestion of whole $X$. laevis DNA with restriction endonuclease HindIII, contains all of the nontranscribed spacer and the $40 \mathrm{~S}$ rRNA precursor coding sequence [Morgan et al., 1980]. Only the conserved coding sequence of this $X$. laevis rDNA sample is expected to hybridize with the chromosomal rDNA. The pXlr 101A probe was labeled with biotin-16-dUTP by nick translation [Langer et al., 1981]. Size distribution of the labeled probe fragments was controlled as described by Lichter et al. [1988]. The biotinylated probe was separated from the unincorporated nucleotides by passage over a Sephadex G-50 column in the presence of $0.1 \%$ SDS. Chromosome preparations were denatured for $1-2 \mathrm{~min}$ in $70 \%$ formamide, $2 \times$ SSC ( $\mathrm{pH} 7.0$ ), and dehydrated by passage through an ice-cold ethanol series. Then, $25 \mu$ l hybridization mixture $(50 \%$ formamide, $5 \%$ dextran sulfate and $20 \mathrm{ng}$ biotinylated pXlr $101 \mathrm{~A}$ probe in $2 \times \mathrm{SSC}$ ) was denatured for $5 \mathrm{~min}$ at $75^{\circ} \mathrm{C}$ and applied to the slides. In situ hybridization and detection of the hybridized probe, as well as the microscopic analysis were performed according to Schmid et al. [2010].

\section{Photography and Analysis of Banding Patterns}

All the microscopic analyses were performed with Zeiss photomicroscopes III and Zeiss Axiophot microscopes equipped with incident HBO 50W mercury lamp illumination. The filter combinations necessary for the analyses of metaphases stained with the various fluorochromes or for the fluorescence in situ hybridizations (FISH) were described by Schmid et al. [2010]. At least 5 karyotypes for each of the staining techniques applied were prepared from each of the animals examined.

\section{DNA Flow Cytometry}

Blood samples of 7 T. rapicauda specimens (4 ㅇ, $3 \sigma^{7}$ ) from Venezuela were obtained by cardiac puncture with a heparinized syringe and fixed immediately in $70 \%$ ethanol. The samples were centrifuged ( $10 \mathrm{~min}, 200 \mathrm{~g}$ ), and the erythrocyte pellets resuspended and incubated in $1 \mathrm{ml}$ pepsin solution $(0.5 \%$ in $0.1 \mathrm{~N} \mathrm{HCl})$ at room temperature for $15 \mathrm{~min}$. After addition of $5 \mathrm{ml}$ staining solution $(2 \mu \mathrm{g} / \mathrm{ml}$ DAPI in $0.2 \mathrm{M}$ sodium citrate), the erythrocyte suspensions were kept at room temperature for $3 \mathrm{~h}$ [Otto, 1994] and were then mixed with chicken erythrocytes. Flow cytometric analyses were carried out with an epi-illumination flow system of conventional design (Partec Cell Analyzer CA II) at $365 \mathrm{~nm}$ (filter combination KG1/BG38/UG1 for excitation, TK420 as dichroic mirror, and GG435 as barrier filter). The nuclear DNA contents were calibrated against the known genome size of chicken erythrocytes $(2.33 \mu \mathrm{g}$ DNA/nucleus) used as internal standards.

\section{Results}

\section{Conventional Staining}

The karyotypes of all T. rapicauda specimens collected in the 4 populations in the Falcón State of northern Venezuela consist of $2 n=44$ telocentric chromosomes gradually decreasing in size (fig. 2). The fundamental number is $\mathrm{FN}=44$. The chromosome pair 1 is distinctly larger than the other pairs. There are no microchromosomes present in this species. Secondary constrictions are not visible in the conventionally stained chromosomes. In the male karyotypes, the 44 chromosome pairs can be arranged in 22 homologous pairs (fig. 2c), whereas in the female karyotypes there is a clearly heteromorphic ZW sex chromosome pair (fig. $2 \mathrm{a}, \mathrm{b}$ ). The $\mathrm{W}$ chromosome is nearly twice the size of the $\mathrm{Z}$ chromosome. It should be noted that, due to the morphological similarity of the larger telocentric chromosomes, the heteromorphic ZW sex chromosomes can be easily overlooked in conventionally stained preparations. Thus, in female karyotypes, it is possible to arrange the chromosomes into pairs where the ZW sex chromosomes are paired with autosomes of similar sizes. 


\section{Banding Analyses}

C-banding unequivocally demonstrates heteromorphic ZW sex chromosomes in the female karyotypes of $T$. rapicauda (fig. 3a-f). The length difference between the $\mathrm{Z}$ and $\mathrm{W}$ chromosomes is caused by a large heterochromatic segment inserted in the distal third of the $\mathrm{W}$ chromosome. The $\mathrm{Z}$ chromosome shows no specific $\mathrm{C}$-banding patterns. The euchromatic segments in the ZW chromosomes are still of the same size. In most chromosomes of T. rapicauda, constitutive heterochromatin is located at the pericentromeric and telomeric regions (fig. $3 \mathrm{a}-\mathrm{d}$, g, h). In preparations over-denatured by the $\mathrm{Ba}(\mathrm{OH})_{2}$ treatment, the pericentromeric and telomeric heterochromatin disappears, whereas the $\mathrm{W}$ chromosome-specific interstitial heterochromatin persists (fig. 3e, f). This differing sensitivity of constitutive heterochromatin against prolonged alkaline pretreatment was also observed in the chromosomes of amphibians [Schmid, 1978] and mammals [Hsu and Arrighi, 1971] and is indicative of the structural heterogeneity of constitutive heterochromatin. In metaphases showing a high degree of chromosome condensation, the $\mathrm{W}$ chromosome-specific interstitial heterochromatin appears to be in a terminal position (fig. 3j).

Staining of T. rapicauda chromosomes with the GC base pair-specific mithramycin results in a distinct dull fluorescence of the $\mathrm{W}$ chromosome-specific interstitial heterochromatin (fig. 4a, e). Conversely, the AT base pair-specific fluorochromes quinacrine, DAPI and Hoechst 33258 induce a somewhat brighter fluorescence in the $\mathrm{W}$-specific heterochromatin than in the rest of the chromosome (figs. 4b, c, f, g, 5a). Counterstaining the chromosomes with distamycin A/DAPI reveals no specific bright fluorescence in the $\mathrm{W}$ chromosome (fig. 5b).

FISH with the $18 \mathrm{~S}+28 \mathrm{~S}$ rDNA probe shows 2 signals in the telomeric regions of autosome pair 11 (fig. 4c, d). Correspondingly, silver staining reveals the NOR in the same chromosome site (fig. $4 \mathrm{~d}^{\prime}$ ).

The 2 specimens of $T$. rapicauda from an unknown wild population in Guatemala have a diploid chromosome number $2 \mathrm{n}=44$ and $\mathrm{FN}=44$ (fig. $6 \mathrm{a}, \mathrm{c}$ ). All chromosomes have a telocentric morphology, and again the chromosomes 1 are distinctly larger than the remaining chromosomes. However, in contrast to the specimens from the Falcón State in northern Venezuela, the female does not possess heteromorphic ZW sex chromosomes (fig. 6a). The C-banding pattern in the chromosomes of both animals is the same as in the karyotypes of the Venezuelan species, except for the presence of the $\mathrm{W}$-specific heterochromatin (fig. 6b, d).

\section{Genome Sizes}

The genome size of $T$. rapicauda was determined using DNA flow cytometry of DAPI-stained erythrocytes of 4 females and 3 males collected in Venezuela. The mean genome size measured in female erythrocytes is $4.01 \mathrm{pg}$ DNA/nucleus, whereas in male erythrocytes it is $3.9 \mathrm{pg}$ DNA/nucleus. As an example of these measurements, the histograms obtained for 1 male and 1 female each are shown in figure 7 . It is necessary to note that the erythro-

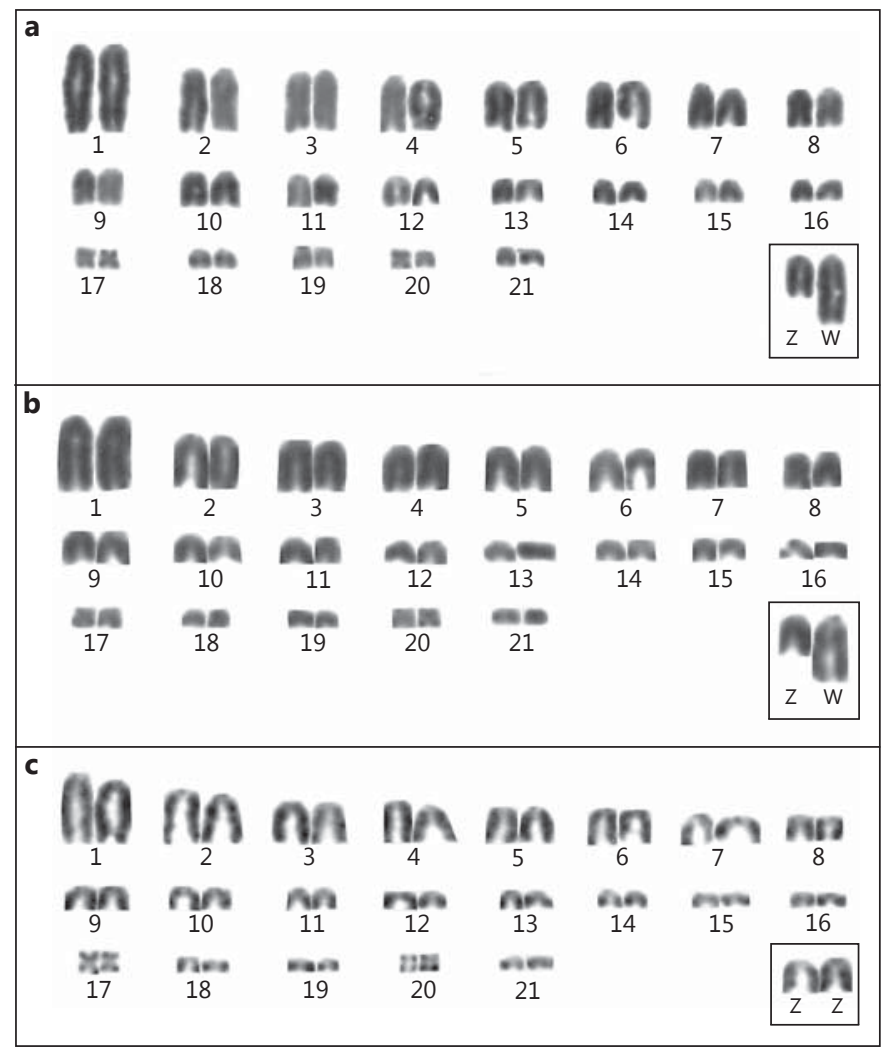

Fig. 2. Conventionally stained karyotypes of female (a, b) and male (c) T. rapicauda from the Falcón State in northern Venezuela. The sex chromosomes are framed.

Fig. 3. a C-banded metaphase of a female T. rapicauda from the Falcón State in northern Venezuela. Note the heteromorphic ZW sex chromosomes and the prominent interstitial heterochromatic segment located in the $\mathrm{W}$ chromosome. b Female karyotype constructed from the chromosomes shown in a. c-h C-banded karyotypes of female (c-f) and male $(\mathbf{g}, \mathbf{h})$ T. rapicauda. The chromosomes in $\mathbf{e}$ and $\mathbf{f}$ were over-denatured. $\mathbf{i}$ Selected ZW sex chromosome pairs. j Over-condensed ZW sex chromosome pairs from late metaphase. Bars $=10 \mu \mathrm{m}$.

(For figure see next page.) 


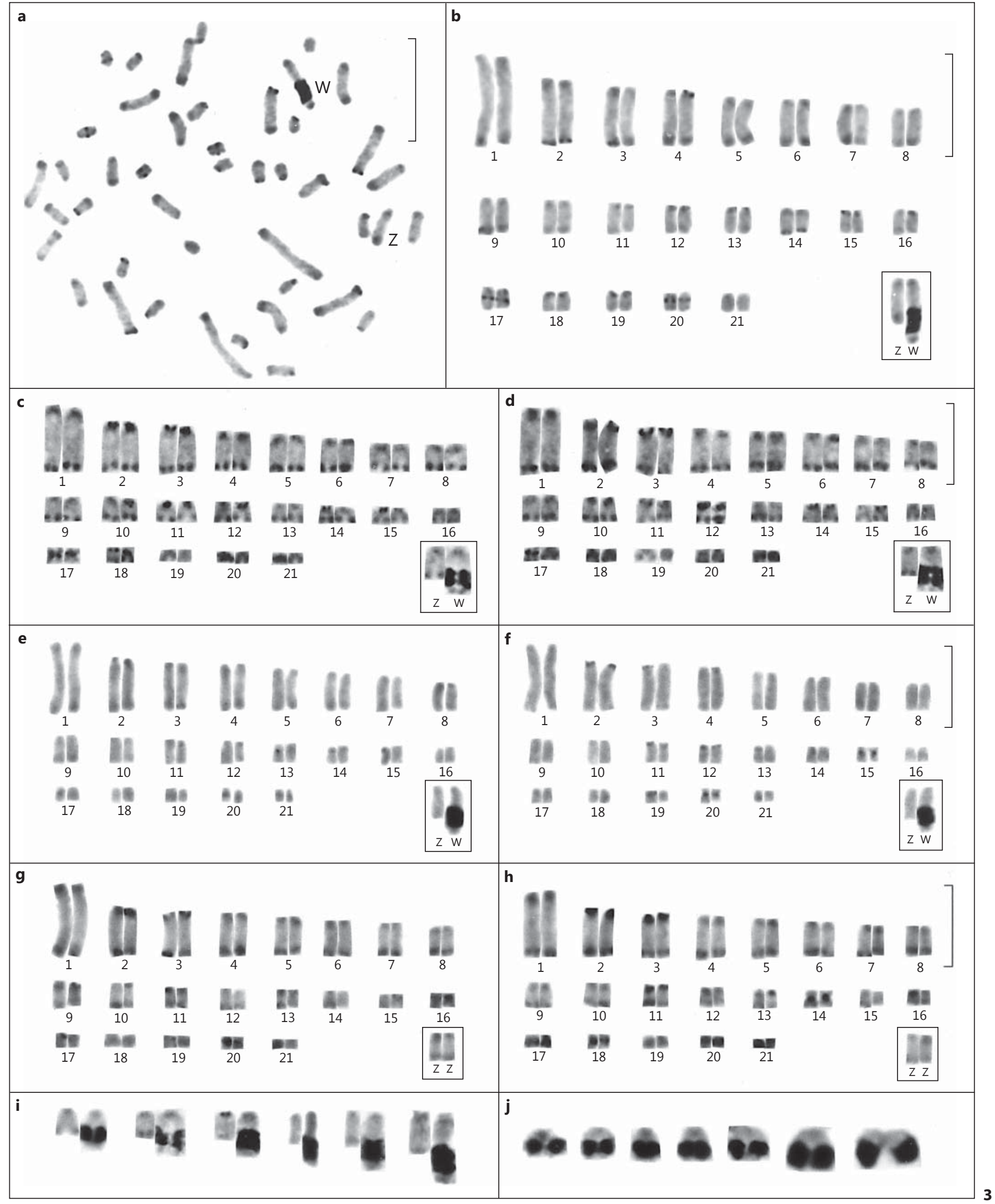

ZW Sex Chromosomes in Thecadactylus

Cytogenet Genome Res 2014;143:259-267

263 rapicauda

DOI: $10.1159 / 000366212$ 
cytes were stained with the AT base pair-specific DAPI and not with ethidium bromide which anneals to doublestranded DNA regardless of its base pair composition. Therefore, the erythrocyte nuclei of female T. rapicauda
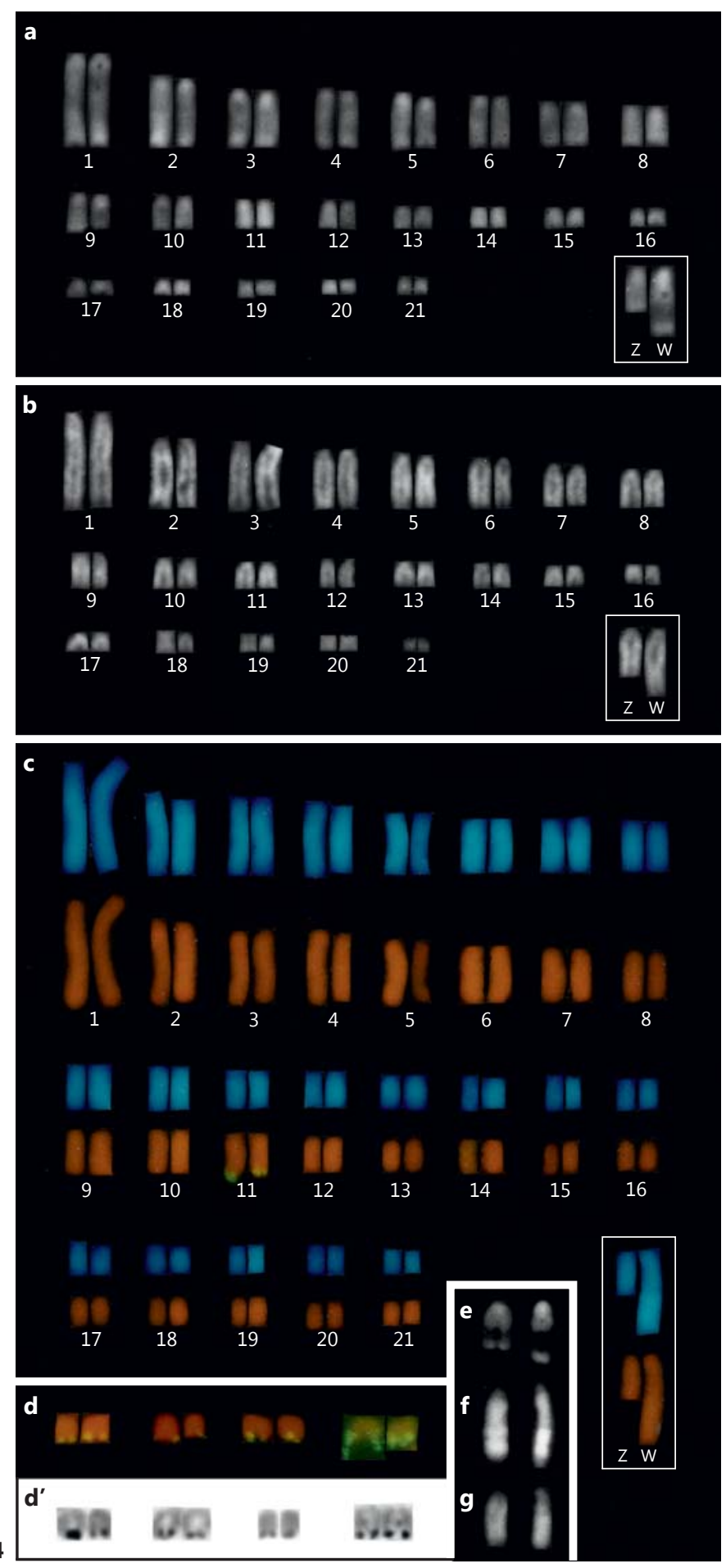

with the large $\mathrm{W}$ chromosome-specific heterochromatin containing high amounts of AT-rich repetitive DNA will be more intensively labeled than the erythrocyte nuclei of males containing $2 \mathrm{Z}$ chromosomes. This can lead to biased DNA values for the female erythrocyte nuclei. Using Feulgen densitometry, Soma et al. [1975] determined the genome size of T. rapicauda with 4.20 pg DNA/erythrocyte nucleus, which is very close to the values measured in the present study.

\section{Discussion}

Evidence for the existence of heteromorphic sex chromosomes in the family Phyllodactylidae was found so far only in Phyllodactylus lanei from the Guerrero State in
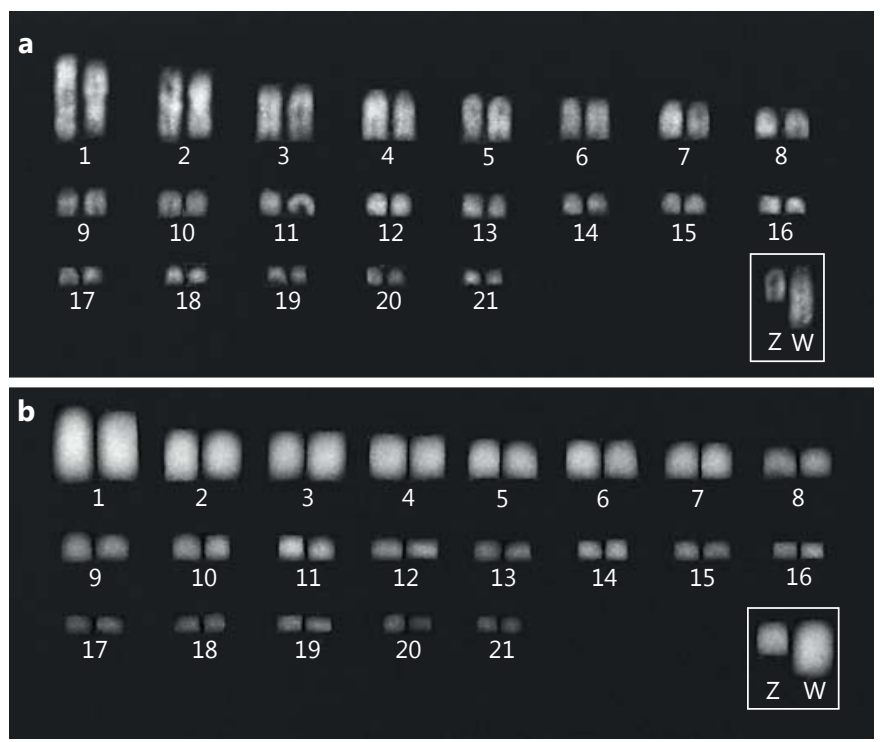

Fig. 5. Karyotypes of female T. rapicauda from the Falcón State in northern Venezuela. a Hoechst 33258 staining. b Distamycin A/DAPI counterstaining.

Fig. 4. a-c Karyotypes of female T. rapicauda from the Falcón State in northern Venezuela. a Distamycin A/mithramycin staining. b Quinacrine mustard staining. c Direct DAPI staining (above) and FISH with an $18 \mathrm{~S}+28 \mathrm{~S}$ rDNA probe (below). The ZW sex chromosomes are framed. d Selected autosome pairs 11 showing the terminal location of the $18 \mathrm{~S}+28 \mathrm{~S}$ rDNA. d' Selected autosome pairs 11 from Ag-stained metaphases showing the terminal location of the NORs. e-g Selected ZW sex chromosome pairs showing distamycin A/mithramycin (e), quinacrine mustard (f) and direct DAPI (g) staining. 
western Mexico [King, 1981]. However, Castiglia et al. [2009] could not confirm such sex chromosomes in specimens collected in the Jalisco State, Mexico. Therefore, either the heteromorphic sex chromosomes are geographically restricted in P. lanei, or 2 different Phyllodactylus species were examined in these 2 studies [Gamble, 2010].

The heteromorphic ZW sex chromosomes found in the present study in T. rapicauda from several populations in the Falcón State in Northern Venezuela are in a nascent stage of differentiation. The only morphological difference between the $\mathrm{Z}$ and $\mathrm{W}$ chromosomes seems to be the inserted prominent heterochromatic band in the $\mathrm{W}$ chromosome. In a study on sex chromosomes and W interphase chromatin in snakes, Ray-Chaudhuri et al. [1971] concluded, for the first time, that heterochromatinization of the $\mathrm{W}$ chromosome can be the primary step in the evolution of heteromorphic ZW sex chromosomes. This was later confirmed in investigations on constitutive heterochromatin and a W chromosome-associated repetitive satellite DNA in snakes [Singh et al., 1976; Jones and Singh, 1981; Jones, 1983a, b, 1984]. Thus, analytical density gradient centrifugation of DNA and in situ hybridization on metaphase chromosomes revealed a specific satellite DNA that is located in the highly differentiated W chromosomes of advanced snake families. The same $\mathrm{W}$-associated DNA was also demonstrated in those highly evolved snake species that still possess undifferentiated (homomorphic) ZW sex chromosomes. Also in amphibians, a number of the known sex chromosomes support the assertion that one of the initial steps in the evolution of sex chromosomes was an accumulation of repetitive DNA in the original $\mathrm{W}$ and $\mathrm{Y}$ chromosomes [for reviews, see Schmid et al., 2010, 2012]. In contrast to mammals, birds and snakes, the $\mathrm{W}$ and $\mathrm{Y}$ chromosomes found in lizards are larger than the $\mathrm{Z}$ and $\mathrm{X}$ chromosomes. This is caused by the amplification of the $\mathrm{W}$ - and Y-associated constitutive heterochromatin [Ezaz et al., 2009a].

Sex chromosomes in reptiles are not derived from the same ancient chromosome pair but originated independently from one another. Thus, comparative gene mapping studies have shown that the ZW sex chromosomes of snakes, the turtle Pelodiscus sinensis, the gecko Gekko hokouensis, and the dragon lizard Pogona vitticeps are not homeologous [Matsuda et al., 2005; Matsubara et al.,

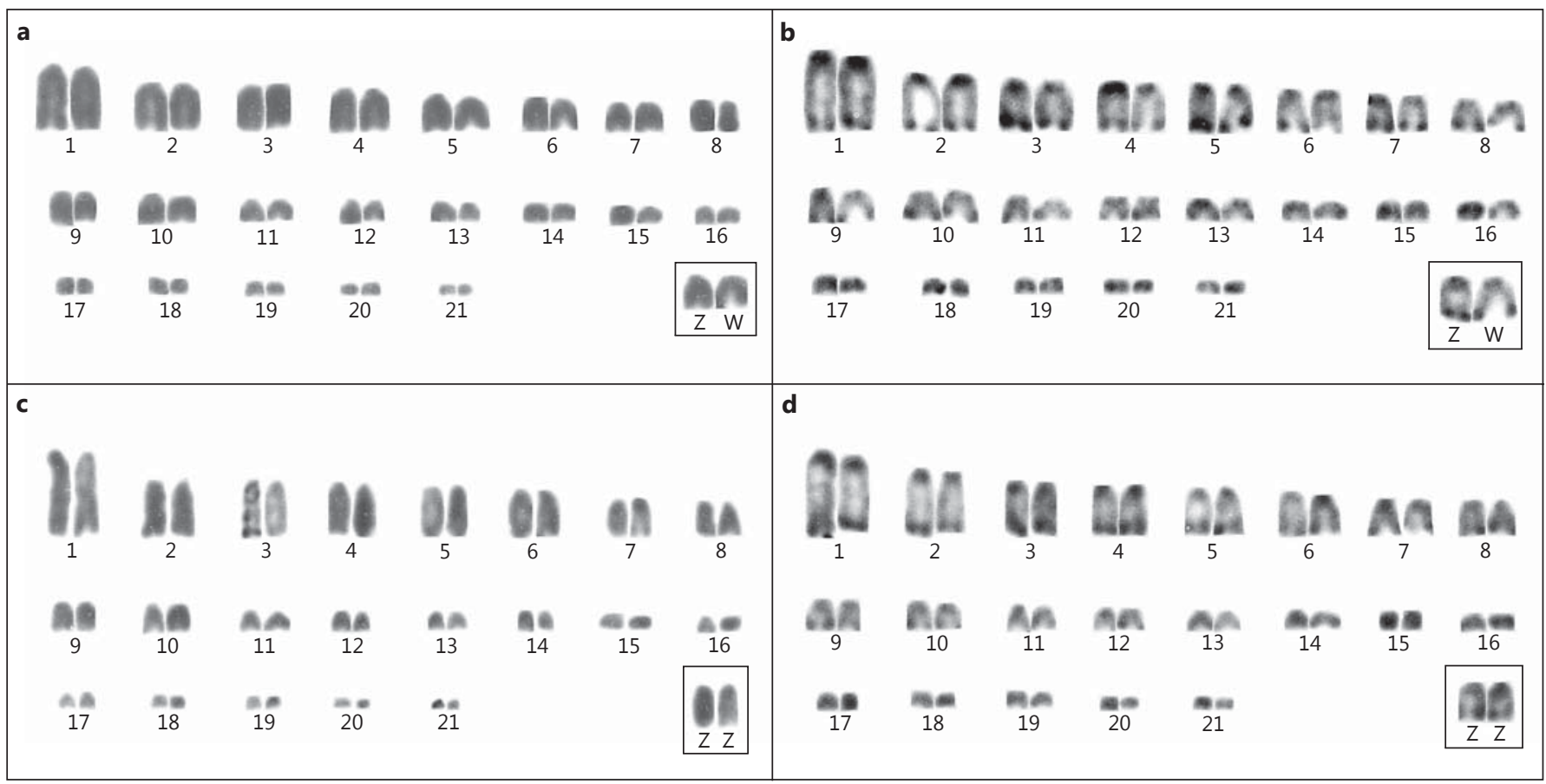

Fig. 6. Karyotypes of female (a, b) and male (c, d) T. rapicauda collected from an unknown locality in Guatemala. a, c Conventional staining. b, d C-banding. The presumed homomorphic sex chromosomes are framed. Compare with figures 2 and 3.

ZW Sex Chromosomes in Thecadactylus rapicauda
Cytogenet Genome Res 2014;143:259-267 DOI: $10.1159 / 000366212$ 


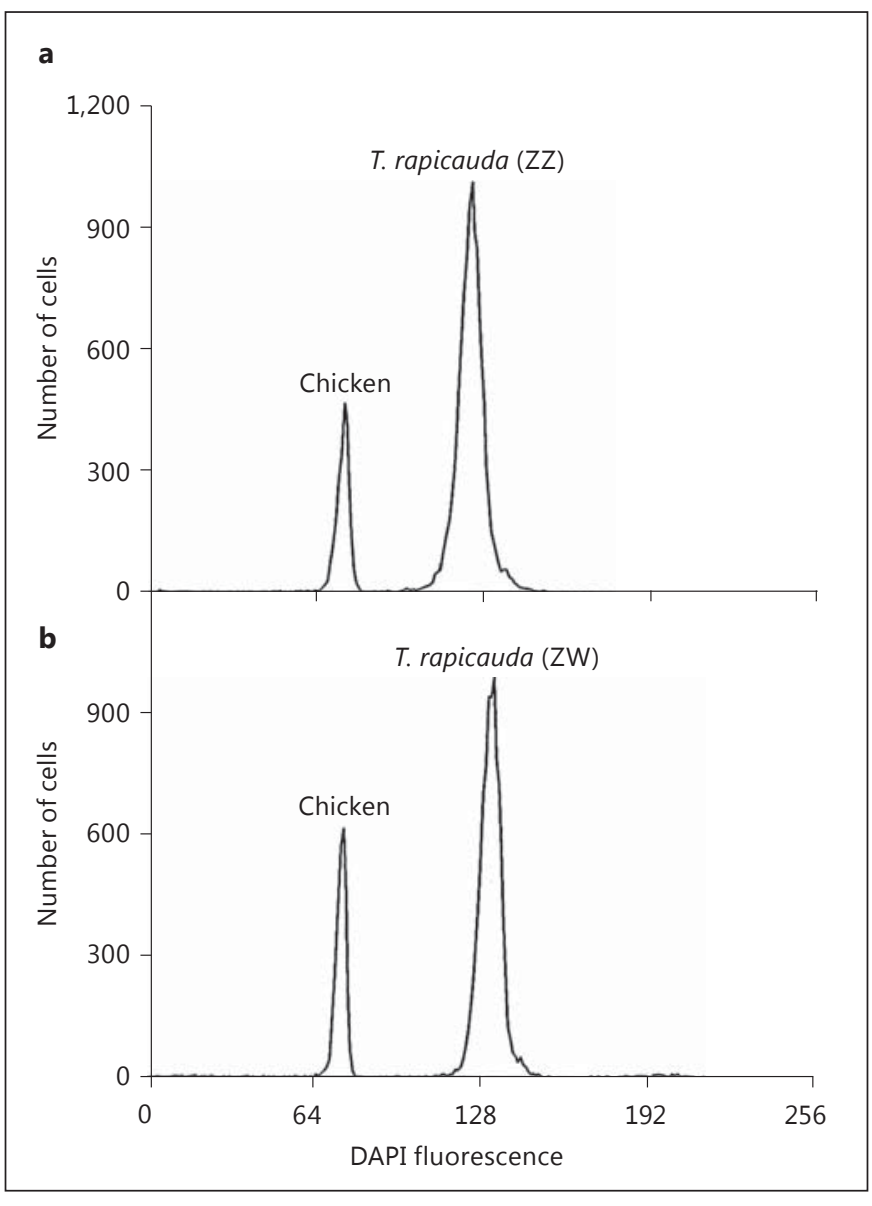

Fig. 7. Histograms obtained by DNA flow cytometry of a mixture of DAPI-stained erythrocytes of chicken and male (a) and female (b) T. rapicauda from the Falcón State in northern Venezuela. The nuclear DNA content is directly proportional to the DAPI fluorescence intensity, expressed as channel numbers on the $\mathrm{x}$-axis. Chicken erythrocytes were used as internal standard with a known DNA content of $2.33 \mathrm{pg}$ DNA/nucleus. The nuclear DNA content of the T. rapicauda erythrocytes is calculated from the ratio of the peak channel number of the T. rapicauda erythrocytes and chicken multiplied by the known nuclear DNA amount of the chicken.

2006; Kawai et al., 2007, 2009; Ezaz et al., 2009b; Kawagoshi et al., 2009].

Since the $\mathrm{W}$ chromosome in the T. rapicauda from the Falcón State is still in a primitive stage of differentiation, it is conceivable that it has a relatively recent origin and is restricted to this region. Thus, in the C-banded preparations from the single female T. rapicauda specimen collected in an unknown wild population in Guatemala, no heteromorphic ZW sex chromosomes were detected.

McBee et al. [1984] analyzed the karyotypes of 2 male T. rapicauda specimens from Caripito in the Monagas
State in northeastern Venezuela. This population is approximately $800 \mathrm{~km}$ (beeline) apart from the Falcón populations examined in the present study. In both males, they found a diploid chromosome number $2 n=42$ and $\mathrm{FN}=44$ (table 1 ) with 1 large pair of submetacentric and 20 pairs of telocentric chromosomes gradually decreasing in size. Obviously this karyotype is derived from the $2 \mathrm{n}=$ 44 and $\mathrm{FN}=44$ by a centric fusion between the largest and one of the medium-sized autosomes. Centric (Robertsonian) fusions were also found in heterozygous and homozygous conditions in another phyllodactylid species, Gymnodactylus amarali from central Brazil [Pellegrino et al., 2009], and are not infrequent among reptiles [Olmo, 1986].

Given the very broad geographic distribution of T. rapicauda from southeastern Mexico through Central America to South America (Colombia, Venezuela, Guyana, Surinam, French Guiana, and northern Brazil) including many Lesser Antillean Islands, further extensive cytogenetic studies can be performed on the karyotype variability of this lizard species.

\section{Acknowledgements}

We are indebted to the personnel of the Instituto de Zoología Agrícola, University of Venezuela (Maracay) for their assistance. We thank Alberto Fernández Badillo (Venezuela) for establishing a temporary cytogenetic laboratory. The dedicated field work of Richar Visbal García and Jesús Manzanilla Pupo (Venezuela) is appreciated. Simone Gruber (Brazil) has helped in obtaining published literature. This study was supported by the Deutsche Forschungsgemeinschaft (Schm 484/7-1, 10-1, 15-1, 15-2) and the Volkswagen Foundation (VW/I/72 515).

\section{References}

Avila-Pires TCS: Lizards of the Brazilian Amazonia (Reptilia: Squamata). Zoologische Verhandelingen. (Backhuys Publishers, Leiden 1995).

-Bergmann PJ, Russell AP: Systematics and biogeography of the widespread Neotropical gekkonid genus Thecadactylus (Squamata), with the description of a new species. Zool J Linn Soc 149:339-370 (2007).

Bickham JW: Patterns and modes of chromosomal evolution in reptiles, in Sharma AK, Sharma A (eds): Chromosomes in Evolution of Eukaryotic Groups, pp 13-40 (CRC Press, Boca Raton 1984).

-Castiglia R, García A, Bezerra AMR, Flores-Villela O, Gornung E: Karyotypic diversification due to Robertsonian rearrangements in Phyllodactylus lanei Smith 1935 (Squamata, Gekkonidae) from Mexico. Rendiconti Lincei Scienze Fisiche e Naturali 20:77-82 (2009). 
Cole CJ, Lowe CH, Wright JW: Sex chromosomes in lizards. Science 155:1028-1029 (1967).

Ezaz T, Sarre SD, O’Meally D, Graves JA, Georges A: Sex chromosome evolution in lizards: independent origins and rapid transitions. $\mathrm{Cy}$ togenet Genome Res 127:249-260 (2009a).

-Ezaz T, Moritz B, Waters PD, Marshall Graves JA, Georges A, Sarre SD: The ZW sex microchromosomes of an Australian dragon lizard share no homology with those of other reptiles or birds. Chromosome Res 17:965-973 (2009b).

Gamble T: A review of sex determining mechanisms in geckos (Gekkota: Squamata). Sex Dev 4:88-103 (2010)

Hsu TC, Arrighi FE: Distribution of constitutive heterochromatin in mammalian chromosomes. Chromosoma 34:243-253 (1971).

- Jones KW: Evolutionary conservation of sex-specific DNA sequences. Differentiation 23 (Suppl):S56-S59 (1983a).

Jones KW: Evolution of sex chromosomes, in Johnson MH (ed): Development in Mammals, vol 5, pp 297-319 (Elsevier Science Publishers, Amsterdam 1983b).

Jones KW: The evolution of sex chromosomes and their consequences for the evolutionary process, in Bennett MD, Gropp A (eds): Chromosomes Today 8:241-255 (1984).

-Jones KW, Singh L: Conserved repeated DNA sequences in vertebrate sex chromosomes. Hum Genet 58:46-53 (1981).

- Kawagoshi T, Uno Y, Matsubara K, Matsuda Y, Nishida C: The ZW micro-sex chromosomes of the Chinese soft-shelled turtle (Pelodiscus sinaensis, Trionychidae, Testudines) have the same origin as chicken chromosome 15. Cytogenet Genome Res 125:125-131 (2009).

Kawai A, Nishida-Umehara C, Ishijima J, Tsuda Y, Ota H, Matsuda Y: Different origins of bird and reptile sex chromosomes inferred from comparative mapping of chicken Z-linked genes. Cytogenet Genome Res 117:92-102 (2007).

Kawai A, Ishijima J, Nishida C, Kosaka A, Ota H, et al: The ZW sex chromosomes of Gekko hokouensis (Gekkonidae, Squamata) represent highly conserved homology with those of avian species. Chromosoma 118:43-51 (2009).

King M: The evolution of sex chromosomes in lizards, in Calaly J, Tyndale-Biscoe H (eds): Evolution and Reproduction, pp 55-60 (Australian Academy of Science, Canberra 1977).
King M: Chromosome change and speciation in lizards, in Atchley W, Woodruff D (eds): Evolution and Speciation. Essays in Honor of MJD White, pp 262-285 (Cambridge University Press, Cambridge 1981).

Köhler G, Vesely M: A new species of Thecadactylus from Sint Maarten, Lesser Antilles (Reptilia, Squamata, Gekkonidae). ZooKeys 118: 97-107 (2011).

Langer PR, Waldrop AA, Ward DC: Enzymatic synthesis of biotin-labeled polynucleotides: novel nucleic acid affinity probes. Proc Natl Acad Sci USA 78:6633-6637 (1981).

- Lichter P, Cremer T, Borden J, Manuelidis L, Ward DC: Delineation of individual human chromosomes in metaphase and interphase cells by in situ suppression hybridization using recombinant DNA libraries. Hum Genet 80:224-234 (1988).

- Matsubara K, Tarui H, Toriba M, Yamada K, Nishida-Umehara C, et al: Evidence for different origin of sex chromosomes in snakes, birds, and mammals and step-wise differentiation of snake sex chromosomes. Proc Natl Acad Sci USA 103:18190-18195 (2006).

Matsuda Y, Nishida-Umehara C, Tarui H, Kuroiwa A, Yamada K, et al: Highly conserved linkage homology between birds and turtles: bird and turtle chromosomes are precise counterparts of each other. Chromosome Res 13:601615 (2005)

McBee K, Sites JW, Engstrom MD, Rivero-Blanco C, Bickham JW: Karyotypes of four species of neotropical gekkos. J Herpetol 18:83-84 (1984).

-Morgan GT, Macgregor HC, Colman A: Multiple ribosomal gene sites revealed by in situ hybridization of Xenopus rDNA to Triturus lampbrush chromosomes. Chromosoma 80: 309-330 (1980).

Moritz C: The evolution of a highly variable sex chromosome in Gehyra purpurascens (Gekkonidae). Chromosoma 90:111-119 (1984).

Olmo E: Reptilia, in John B (ed): Animal Cytogenetics, Vol 4/3 (Gebrüder Borntraeger, Berlin 1986).

Olmo E, Signorino G: Chromorep: a reptiles chromosomes database. http://ginux.univpm.it/scienze/chromorep/introduzione. html (2005).
Olmo E, Odierna G, Capriglione T: Evolution of sex chromosomes in lacertid lizards. Chromosoma 96:33-38 (1987).

Otto FJ: High-resolution analysis of nuclear DNA employing the fluorochrome DAPI, in Darzynkiewicz Z, Robinson JP, Crissman HA (eds): Methods in Cell Biology, Vol 41, Flow Cytometry, pp 211-217 (Academic Press, San Diego 1994).

Pellegrino KCM, dos Santos RML, Rodrigues MT, Laguna MM, Amaro RC, Yonenaga-Yassuda Y: Chromosomal evolution in the Brazilian geckos of the genus Gymnodactylus (Squamata, Phyllodactylidae) from the biomes of Cerrado Caatinga and Atlantic rain forest: evidence of Robertsonian fusion events and supernumerary chromosomes. Cytogenet Genome Res 127:191-203 (2009).

Ray-Chaudhuri SP, Singh L, Sharma T: Evolution of sex-chromosomes and formation of $\mathrm{W}$ chromatin in snakes. Chromosoma 33:239251 (1971).

Russel AP, Bauer AM: Thecadactylus, T. rapicauda. Catalogue of American Amphibians and Reptiles 753:1-16 (2002).

Schmid M: Chromosome banding in Amphibia. II. Constitutive heterochromatin and nucleolus organizer regions in Ranidae, Microhylidae and Rhacophoridae. Chromosoma 68: 131-148 (1978).

-Schmid M, Steinlein C, Bogart JP, Feichtinger W, León $\mathrm{P}$, et al: The chromosomes of terraranan frogs. Insights into vertebrate cytogenetics. Cytogenet Genome Res 130/131:1-568 (2010).

-Schmid M, Steinlein C, Bogart JP, Feichtinger W, Haaf T, et al: The hemiphractid frogs. Phylogeny, embryology, life history, and cytogenetics. Cytogenet Genome Res 138:69-384 (2012).

-Singh L, Purdom IF, Jones KW: Satellite DNA and evolution of sex chromosomes. Chromosoma 59:43-62 (1976).

Soma M, Beçak ML, Beçak W: Estudo comparativo do conteúdo de DNA em 12 espécies de lacertílios. Ciência e Cultura 27:1324-1327 (1975).

Vidal N, Hedges SB: The molecular evolutionary tree of lizards, snakes and amphisbaenians. C R Biol 332:129-139 (2009). 